\title{
Utilization of ceramic materials in the process of electromagnetic wave conversion to heat usable for space heating of residential facilities
}

\author{
Pavel Koštial ${ }^{1, *}$, Zora Koštialová Jančíková ${ }^{1}$, Jozef Vlček $^{1}$, Hana Špačková ${ }^{1}$ and Pavel Klaus ${ }^{1}$ \\ ${ }^{1}$ VSB-Technical university of Ostrava, Faculty of Materials Science and Technology, Czech Republic
}

\begin{abstract}
The work is dedicated to converting microwave radiation to heat. The article analyses different ways of heating residential and utility areas. Attention is paid mainly to infrared heating. Ceramic materials suitable for converting microwave radiation to heat from refractory ceramic composites are disclosed. The cooling curves of these materials after microwave heating are characterized in detail. The paper also presents a description of a microwave reactor with a fireclay brick together with the parameters of the living room heating.
\end{abstract}

\section{Introduction}

The present, modern methods used in most cases for heating of dwelling spaces are particularly based on underfloor heating, ceiling heating, and ceiling cooling, where the primary sources of heat energy are conventional ones, such as electricity, gas or solid fuels, or alternative sources, such as heat pumps, solar energy or wind power [1-13].

Radiation heat is already used for many centuries. The classic conventional heat is supplied, for instance, by a radiator or a typical electric heater (convector), through heating the air in its neighbourhood. At their surface temperature of $90{ }^{\circ} \mathrm{C}$, infrared panel heaters radiate at the wavelength of approx. 9 to $10 \mu \mathrm{m}$, which is a suitable component for human organism influencing the growth of organism cells and psychological comfort. The infrared panels heating all the objects make possible to achieve the so-called "underfloor heating" effect. This means that the floor heated with radiant beams will have the same effect as if a costly underfloor heating is installed. As compared to convection heat, the radiation heat offers several advantages. For its major part, radiation heats - similarly to the sun - only solid things and not air (approx. 1 to $2^{\circ} \mathrm{C}$ ). The advantage consists in the minimum air circulation and the floor-to-ceiling temperature difference is approx. by $1{ }^{\circ} \mathrm{C}$. Therefore, this property is one of many aspects contributing to energy savings. Another factor is the effect of masonry drainage, where the masonry of higher temperature transfers its moisture into the ambient air; by this, its thermal insulation properties are improved. In this way, no mould in the house is any more. The infrared heat is a normal part of our lives - the sun casts on us a whole spectre of electromagnetic waves and the infrared section forms a small part thereof only.
The difference between the standard, mostly convective heating method and the radiation one is shown in Fig. 1. In the first case, the air is heated and it circulates around the room. In the case of the radiation heating, things and walls within reach of the radiation are heated.
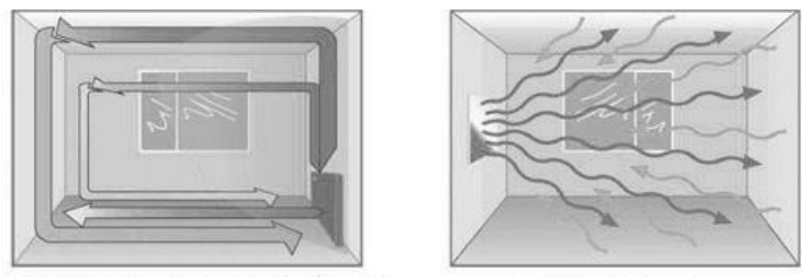

Fig. 1. Standard, mostly convective heating method (left) and radiation heating (right).

The disadvantages of the infrared heating can be summed up as follows. In every space that is intended for heating, a heating panel must be placed; it is not possible to heat up another space with a single panel (e.g. through an open door). The infrared radiation travels in the same manner as light, i.e. there, where is a shadow, no heating of the neighbourhood or ambient air is possible. Therefore, the panel must be situated in a way that no shadow is created in the direction of radiation due to an obstacle (e.g. a cabinet, a three-piece suite, etc.).

Dielectric heating, also known as microwave electromagnetic radiation represents another very efficient method of the radiation heating. Its advantages are as follows [14]:

As opposed to other heating methods, higher temperatures can be achieved by the dielectric heating inside the heating body than on its surface. Because the

Corresponding author: pavel.kostial@,vsb.cz 
material is heated in its whole volume, high uniformity of warming-through is achieved.

\section{Experimental arrangement}

Let us pay our attention to the physical description of heat generation in solid matters. The electric alternating field affects the population of particles forming a dielectric medium, which moves steadily due to the thermal motion.

It is necessary to take into consideration, in a quantitative characterisation of fields Ei(t) affecting the dielectric medium, the final speed of the propagation of the dipole electromagnetic radiation pi(t). Apart from this, it is not possible to neglect kinetic properties of molecules that show themselves, for instance, in the fact that in their mutual interactions relaxation processes come into effect: due to the inertia of individual particles, the size of $\mathrm{p}_{\mathrm{i}}(\mathrm{t})$ at any arbitrary time differs from the stationary values $\mathrm{P}_{\mathrm{i}}\left(\mathrm{E}_{\mathrm{i}}\right)$ corresponding to the immediate value of the inner electric field $E_{i}(t) . P(t)$ is the polarization vector. The electric induction vector $\mathrm{D}(\mathrm{t})=\varepsilon_{0} \mathrm{E}(\mathrm{t})+\mathrm{P}(\mathrm{t})$ is at every point of the dielectric medium volume determined by its structural properties and size of the total medium macroscopic field $\mathrm{E}(\mathrm{t})$. Proceeding from the assumption that this field is changing in accordance with the applied voltage

$$
U=U_{m} \cos \omega t=U_{m} e^{j \omega t}
$$

where $U_{m}$ is the voltage maximum value, $\omega$ is the circular frequency, then $D(t)$ is changing with time in a sinusoidal manner, but it is phase-delayed at $\mathrm{E}(\mathrm{t})$ for a certain angle $\delta$. This delay is caused mostly by the fact that due to the inertia and mutual reaction of particles, the stationary value of $\mathrm{P}(\mathrm{E})$ is determined with a certain delay in the relation to $E(t)$. The relation between $D(t)$ and $\mathrm{E}(\mathrm{t})$ can be then expressed as

$$
D(t)=D_{m} e^{j(\omega t-\delta)}=\varepsilon_{0} \varepsilon *(\omega) E_{m} e^{j \omega t}
$$

where $\varepsilon^{*}(\omega)=\varepsilon^{\prime}(\omega)-\varepsilon^{\prime \prime}(\omega)$ is the complex permittivity determined by the dielectric medium properties. The $\mathrm{D}(\mathrm{t})$ vector can be divided into two components as follows:

$$
D(t)=D_{c m} e^{j \omega t}+D_{a m} e^{j\left(\omega t-\frac{\pi}{2}\right)}
$$

where

$\mathrm{D}_{\mathrm{cm}}=\varepsilon_{0} \varepsilon^{\prime} \mathrm{E}_{\mathrm{m}}$ is the reactive component amplitude, the phase of which is identical to the phase $\mathrm{E}(\mathrm{t})$,

$\mathrm{D}_{\mathrm{am}}=\varepsilon_{0} \varepsilon^{\prime \prime} \mathrm{E}_{\mathrm{m}}$ is the active component amplitude of the phase shifted by the angle of $\frac{\pi}{2}$,

and where the both component ratio is

$$
\frac{D_{c m}}{D_{a m}}=\frac{\varepsilon^{\prime \prime}}{\varepsilon^{\prime}}=\operatorname{tg} \delta
$$

$\varepsilon^{\prime}=\varepsilon_{\mathrm{r}}$ is the relative permittivity,

$\varepsilon "=\varepsilon_{\mathrm{r}} \operatorname{tg} \delta$ is the loss number, and

$\operatorname{tg} \delta$ is the loss factor.
Dielectric specific losses will be determined according to the following relation:

$$
\begin{aligned}
& p_{a}=\int_{0}^{1} E \frac{d D}{d t} d t=\int_{0}^{\frac{1}{2} f} E_{m} \cos \omega t\left(D_{a m} \cos \omega t-\right. \\
& \left.D_{c m} \sin \omega t\right) d t=\frac{1}{2} \varepsilon_{0} \varepsilon^{\prime \prime} \omega E_{m}^{2}=\varepsilon_{0} \varepsilon^{\prime} t g \delta \omega E^{2}
\end{aligned}
$$

This derived formula takes into the consideration the losses conditioned by polarisation effects. In real dielectric media that are always characterised also by a certain value of conductivity, the conductive component contributes to the losses of electric current passing through the dielectric medium. The current density can be expressed in accordance with Ohm's Law in the form:

$$
J=\gamma \mathrm{E}\left(\mathrm{A} m^{-2}\right),
$$

and the specific losses by the formula:

$$
p_{a}=\gamma E^{2},
$$

where $\mathrm{J}$ is the current density vector, $\gamma$ is the specific conductivity and $\mathrm{E}$ is the electric filled intensity.

If compared with (6), the following result will be obtained:

$$
\operatorname{tg} \delta=\frac{\gamma}{\omega \varepsilon_{0} \varepsilon^{\prime}} ; \varepsilon^{\prime \prime} \frac{\gamma}{\omega \varepsilon_{0}}
$$

The specific dielectric losses are not only the function of the loss factor tg $\delta$, but other variables come into play. The values of frequency or electric field intensity influence the purpose, for which the equipment is intended, i.e. they ensue from the operating conditions. With increasing $\omega$ or $E$, the quality requirements for the dielectric medium always rise as well, usually to a low value of $\operatorname{tg} \delta$. Thus, due to the low dielectric losses, the question of the relative permittivity level can be disregarded as well [15].

The quantity of released heat is mostly influenced by the loss number $\varepsilon$ ", which represents the losses caused by free charge carriers in the monitored material and, of course, by the frequency and field intensity. In Fig. 2, there is shown the frequency dependence of the complex permittivity components, from which it can be seen that the dominant role in the heat development in a real dielectric sample at microwave frequencies is played by dipoles and ions. In Table 1, there are described the conditions of the electromagnetic field propagation by conductivity types [14].

Now, let us pay the attention to the properties of "potential" materials usable for dielectric heating. According to the above-shown analysis, they should contain ions and dipoles in particular. Two-dimensional structures belong among such materials in the first place, such as clays [4-13].

For the preparation of "controversial" materials, fireclays were used. They can be classified according to their $\mathrm{Al}_{2} \mathrm{O}_{3}$ content as follows:

- Fireclay materials: $\mathrm{Al}_{2} \mathrm{O}_{3}$ content from $10 \%$ to $45 \%$ these materials are further divided to acid ones (under $30 \% \mathrm{Al}_{2} \mathrm{O}_{3}$ ) and normal fireclay materials (from $30 \%$ to $45 \% \mathrm{Al}_{2} \mathrm{O}_{3}$ ). 
- High-alumina materials: $\mathrm{Al}_{2} \mathrm{O}_{3}$ content is over $45 \%$; products made of corundum with the $\mathrm{Al}_{2} \mathrm{O}_{3}$ content over $90 \%$ ranks among these materials as well.

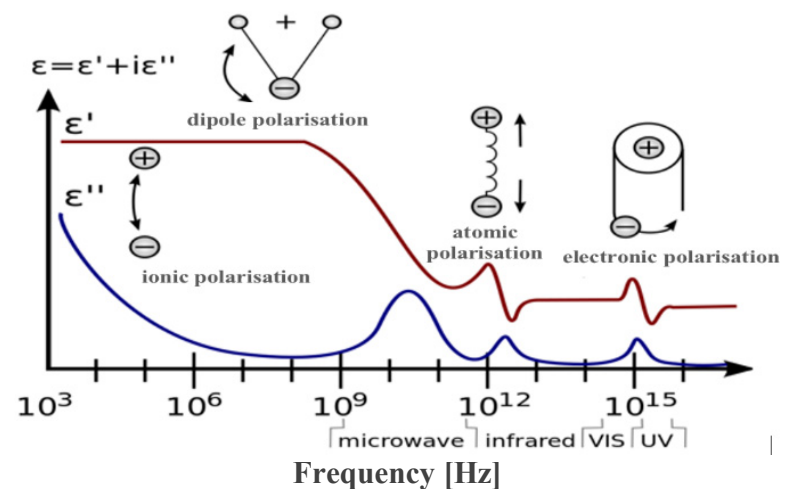

Fig. 2. Frequency dependencies of the dielectric constant [15].

Table 1. Classification of materials in terms of their permittivity according to [15].

\begin{tabular}{|c|c|c|}
\hline $\begin{array}{l}\boldsymbol{\varepsilon}_{\mathbf{r}}{ }^{{ }{ }^{6} /} \\
\boldsymbol{\varepsilon}_{\mathbf{r}}{ }^{{ }}\end{array}$ & Conductivity types & $\begin{array}{c}\text { Electromagnetic field } \\
\text { propagation }\end{array}$ \\
\hline 00 & $\begin{array}{c}\text { Perfect dielectric } \\
\text { material, zero-loss } \\
\text { environment }\end{array}$ \\
\hline$<<1$ & $\begin{array}{c}\text { Low conductivity } \\
\text { materials, poor } \\
\text { conductors }\end{array}$ & $\begin{array}{c}\text { Low-loss environment, } \\
\text { good dielectric material }\end{array}$ \\
\hline$\gtrsim 1$ & $\begin{array}{c}\text { Conductive material, } \\
\text { loss }\end{array}$ & $\begin{array}{c}\text { Loss-inducing } \\
\text { environment }\end{array}$ \\
\hline$\gg 1$ & $\begin{array}{c}\text { High-conductivity } \\
\text { materials, good } \\
\text { conductors }\end{array}$ & $\begin{array}{c}\text { High-loss environment, } \\
\text { poor dielectric medium }\end{array}$ \\
\hline$\infty$ & Perfect conductors & \\
\hline
\end{tabular}

In our experiments, we used the material with its chemical composition as follows: $\mathrm{Al}_{2} \mathrm{O}_{3} \geq 36 \%$ and $\mathrm{Fe}_{2} \mathrm{O}_{3}$ type $2.5 \%$, with the vitrified bond and apparent porosity $\leq 25 \%$. The material was processed into the form of small bricks of dimensions $(4 \times 4 \times 16) \mathrm{cm}^{3}$ and then to large bricks of dimensions $(22 \times 11 \times 5.5) \mathrm{cm}^{3}$. Raw material was supplied by Ceramic, a.s. Vítkovice (Czech Republic).

The small bricks were heated for ten minutes in a microwave oven at its full output $(1,200 \mathrm{~W})$ and $2.45 \mathrm{GHz}$ frequency. Cooling of the sample was measured by a thermocouple in the microwave oven (closed and switched off). The cooling curve for the monitored material is shown in Fig. 3. It can be seen here that the relatively high initial temperature of the small brick (approx. $300^{\circ} \mathrm{C}$ ) was exponentially dropping, bit by bit, down to approx. $100{ }^{\circ} \mathrm{C}$ in the convectiveradiation mode for the period of 30 minutes. The final temperature of the heating process as well as the cooling duration period is interesting in terms of heat accumulation and radiation suitable for space heating. The cooling curve of a fireclay brick with pressed-in metal netting is shown in Fig. 4. As shown in the diagram, the sample final temperature achieved in this case was higher by approx. $150^{\circ} \mathrm{C}$ than with the sample without metal netting.

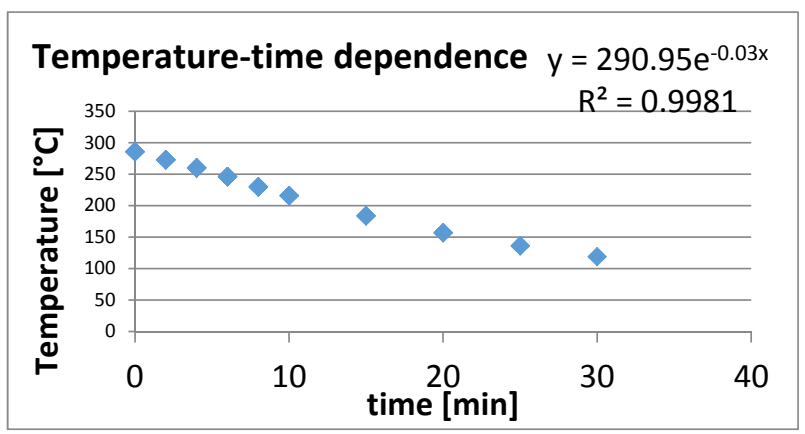

Fig. 3. Sample cooling curve after its exposure in the microwave reactor, pressing force $813 \mathrm{~Pa}$, heating-up 10 minutes, output power $1,200 \mathrm{~W}$ and $2.45 \mathrm{GHz}$ frequency.

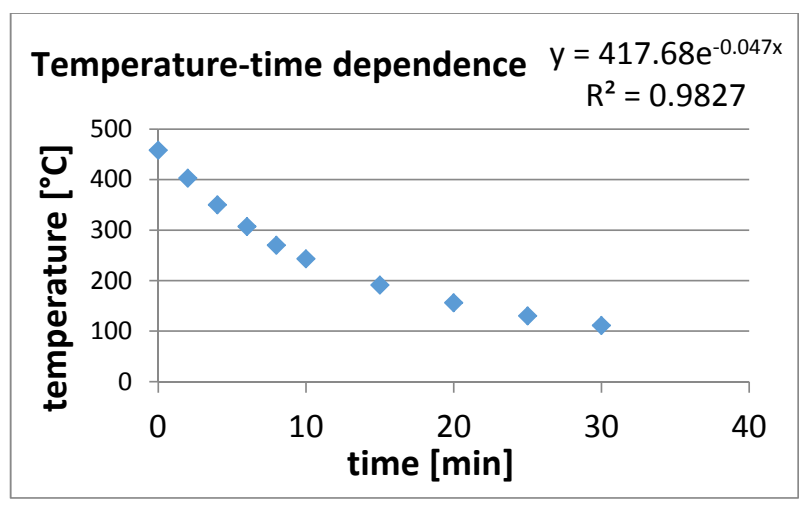

Fig. 4. Sample cooling curve (sample with metal netting) after its exposure in the microwave reactor, pressing force $7813 \mathrm{~Pa}$, heating-up 10 minutes, output power $1,200 \mathrm{~W}$ and $2.45 \mathrm{GHz}$ frequency.

The heat intensity, or in other words, the energy density radiated at a lower temperature (approx. $300{ }^{\circ} \mathrm{C}$ ) was determined by the use of the Stefan-Boltzmann constant for the (absolute) black body and its value was $6,112.2 \mathrm{~W} \cdot \mathrm{m}^{-2}$. In the second case of the higher temperature, the intensity of the electromagnetic radiation equalled to $19,216.8 \mathrm{~W} . \mathrm{m}^{-2}$, which was roughly a triple of the previous value. The electric input was $0.32 \mathrm{kWh}$, which corresponded to the electrical work of $1.15 \mathrm{MJ}$.

The point is - where is this effect concealed?

In this material, water is present both in bound and free state. The bound water depends on the brick mineralogical composition. In principle, for this problem analysis we can use the kaolinite model-driven approach. It is argillaceous material, which is similar and which creates a part of the mass. The bound water releasing takes place at $500{ }^{\circ} \mathrm{C}$ to $600{ }^{\circ} \mathrm{C}$, however this kind of temperature cannot be achieved in a microwave oven.

Free water has a relatively high thermal capacity $c_{p}$ (approx. 4,200 J/ kg. K), which helps in heating the material structure up. The factor influencing heat generation in fireclay also includes the presence of ions. In two-dimensional structures, ions are dislocated between the layers, similarly as water. An example of 
the distribution of atoms in the clay structure is demonstrated in Fig. 5; 3D structural (Fig. 5a) and 2D structural units (Fig. 5b) represent the atom distribution in these material types. Each structural unit is described by the chemical formula $\left[\mathrm{SiO}_{3}\right]^{2--}$. $\mathrm{O}^{-}$ions on the top and side of the chain can create ionic bonds with metal ions.

An important role is also played by the fireclay thermal conductivity, which depends, among other things, also on the grain size, which influences the heat accumulation in the material. However, we did not study this parameter.

The presence of the metal netting in the relevant fireclay sample significantly increased the final temperature after the exposure of the fireclay material to the microwave radiations, which was caused by currents induced in the metal netting due to the microwave presence. Large bricks were prepared from the abovespecified material and they were placed into a special microwave reactor described below.

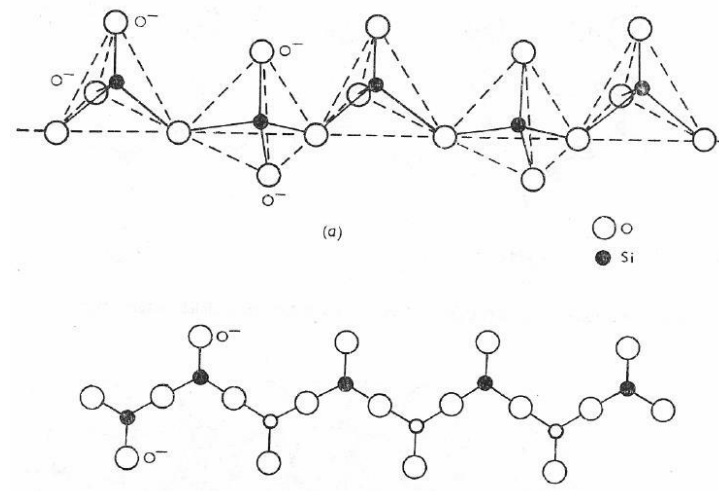

Fig. 5. $\mathrm{SiO}_{4}$ structure.

In order to test the relevant material in a real heating body, we designed a microwave reactor according to the following specification. Electromagnetic radiation radiated from the microwave source is absorbed in the described composite ceramic material, which contains both bound and free water, suitable ions and, in addition, the metal netting. Losses by bond water releasing are minimal. The heating effect even amplifies the presence of metals and ions in the material of conversion and heat accumulating medium, which has to a have sufficiently large thermal capacity under constant pressure. Microwaves converted to heat generated in fireclay are transferred by contact to the heated space over a metal wall. Owing to its relatively high specific electric conductivity, the metal surface functions as a shield of electromagnetic waves preventing their penetration into the heated space.

The described reactor was placed in a warm-padded house in a room of the volume of $39 \mathrm{~m}^{3}$. The consumed electrical input for $45 \mathrm{~min}$ hours of overnight heating equalled to $0,9 \mathrm{kWh}$ and the room was heated up from $19{ }^{\circ} \mathrm{C}$ to $22{ }^{\circ} \mathrm{C}$, which yielded - in conversion to cubic metres of the heated space - the value of $0.02 \mathrm{kWh} / \mathrm{m}^{3}$. As $1 \mathrm{kWh}=3.6 \mathrm{MJ}$, then the electric input of $0,9 \mathrm{kWh}$ represents the electric work of 3,24 MJ. The heat necessary for heating the air in the room can be calculated from the formula $\mathrm{Q}=\rho \mathrm{V}$ c $\Delta \mathrm{t}$, where $\rho, \mathrm{V}, \mathrm{c}$ and $\Delta \mathrm{t}$ are respectively, the specific density, room volume, specific thermal capacity and temperature difference. After the relevant value placements for air, the values $0.15 \mathrm{MJ}$ is obtained. The heat necessary for the brix heating $\left(300{ }^{\circ} \mathrm{C}\right)$ is equal approximately to 0,3 MJ. The water content is not known.

\section{Conclusion}

Sufficient findings from the relevant paper can be summed up as follows: the presented fireclay bricks can be successfully applied as suitable materials for microwave-to-heat conversion. They are predestined to this purpose by the water presence, both bonded and free. In addition, there is the presence of ions usual in such structures, but also pressed-in metal nettings. All these aspects significantly contribute to the efficient transformation of microwave radiation to heat, which is then radiated by contact to the space over the metal wall, which prevents the penetration of microwave radiation into residential premises.

This work was supported by Ministry of Education, Youth and Sports, Czech Republic in the framework of the projects SP2019/17 and SP2019/62 and SP 2019/43.

\section{References}

1. J. Řeháček, A. Janouš, P. Kučera, J. Šafránek, Thermal technical and energy characteristics of buildings (Grada, Praha, 2002)

2. R Karlík, Tepelné čerpadlo pro váš di̊m (Grada, Praha, 2009)

3. M. Halahyja, J. Valášek, Solar energy and its use (Alfa, Bratislava, 1983)

4. J. Lu, X. P. Zhao, Journal of Material chemistry, 12, 2603 (2002)

5. A. Lerf, P. Čapková, American Scientific Publishers, 639 (2004)

6. X. Feng, L. Zhou, Y. Ye, J. F. Chen, JOURNAL OF APPLIED POLYMER SCIENCE, 133, 32 (2016)

7. G. Lagaly, M. Ogawa, I. Dékány, Handbook of Clay Science, 12, 309 (2006)

8. H. Motz, J. Geisler, PERGAMON, 25, 207 (2000)

9. W. Kurdowski, Chemia cementu (Wydawnictwo naukove, Warszawa, 1991)

10. S. Kourounis, Cement and Concrete Research, 37, 815 (2007)

11. D. M. Roy, Cement and Concrete Research, 29, 249 (1999)

12. P. V. Krivenko, D. Roy, Alkali-Activated Cement and Concretes (Taylor \& Francis, London, 2006)

13. A. R. Lee, LEE, Edward Arnold, 119 (1974)

14. V. D. Vera, Dielectric relaxation (Academic press, London and New York, 1967)

15. J. Krempaský, Fyzika. Učebnica pre vysoké školy technické (Alfa Bratislava, SNTL Praha, 1982) 